\title{
Solubility in Binary Solvent Systems: 8. Estimation of Binary Alkane plus $p$-Dioxane Solvent Nonideality from Measured Anthracene Solubilities
}

\author{
Alexander D. Procyk, Margaret Bissell, Kenneth W. Street, Jr., and \\ William E. ACREE, JR. ${ }^{x}$
}

Received November 26, 1986, from the Department of Chemistry, Kent State University, Kent, OH 44242. Accepted for publication April 28, 1987.

\begin{abstract}
Experimental solubilities are reported for anthracene in binary solvent mixtures containing $p$-dioxane with $n$-hexane, cyclohexane, $n$-heptane, methylcyclohexane, $n$-octane, cyclooctane, and isooctane at $25^{\circ} \mathrm{C}$. Results of these measurements, used in conjunction with the nearly ideal binary solvent (NIBS) model, enabled excess Gibbs free energies, $\Delta \bar{G}_{B C}^{\mathrm{h}}$, of the seven binary solvent mixtures to be estimated. Estimated values for $p$-dioxane plus cyclohexane, $p$-dioxane plus $n$ heptane, and $p$-dioxane plus methylcyclohexane mixtures are in reasonable agreement with published values based on vapor pressure measurements.
\end{abstract}

The use of binary solvents for influencing solubility and multiphase partitioning has many potential applications in the pharmaceutical industry. In an earlier paper, Acree et al. ${ }^{1}$ extended the basic nearly ideal binary solvent (NIBS) model to systems containing association between the solute (component A) and a complexing cosolvent (component C):

$$
\begin{aligned}
& \mathrm{A}_{1}+\mathrm{C}_{1} \rightleftharpoons \mathrm{AC} \\
& K_{\mathrm{AC}}^{\phi}=\frac{\phi_{\mathrm{AC}}}{\phi_{\mathrm{A}_{1}} \phi_{\mathrm{C}_{1}}}
\end{aligned}
$$

A relatively simple expression was developed for the determination of solute-solvent equilibrium constants from the measured solubility as a function of solvent composition and the excess Gibbs free energy of the binary solvent mixture:

$$
\begin{array}{r}
R T\left[\ln \left(\mathrm{a}_{\mathrm{A}}^{\mathrm{solid}} / \phi_{\mathrm{A}_{1}}^{\mathrm{sat}}\right)-1+\bar{V}_{\mathrm{A}}\left(\frac{\phi_{\mathrm{A}_{1}}^{\mathrm{sat}}}{\bar{V}_{\mathrm{A}}}+\frac{\phi_{\mathrm{B}}}{\bar{V}_{\mathrm{B}}}+\frac{\phi_{\mathrm{C}}}{\bar{V}_{\mathrm{C}}}\right)\right]= \\
\left(1-\phi_{\mathrm{A}}^{\mathrm{sat}}\right)^{2}\left[\phi_{\mathrm{B}}^{\mathrm{o}}\left(\Delta \bar{G}_{\mathrm{A}}^{\mathrm{fh}}\right)_{\mathrm{B}}^{*}+\phi_{\mathrm{C}}^{\mathrm{o}}\left(\Delta \bar{G}_{\mathrm{A}}^{\mathrm{fh}}\right)_{\mathrm{C}}^{*}-\right. \\
\left.\bar{V}_{\mathrm{A}}\left(X_{\mathrm{B}}^{\mathrm{o}} \bar{V}_{\mathrm{B}}+X_{\mathrm{C}}^{\mathrm{o}} \bar{V}_{\mathrm{C}}\right)^{-1} \Delta \bar{G}_{\mathrm{BC}}^{\mathrm{fh}}\right]
\end{array}
$$

with the overall volume fraction solubility, $\phi_{\mathrm{A}}^{\text {sat }}$, being related to the solubility of the uncomplexed solute and the equilibrium constant by

$$
\phi_{\mathrm{A}}^{\mathrm{sat}}=\phi_{\mathrm{A}_{1}}^{\mathrm{sat}}\left[1+\bar{V}_{\mathrm{A}} K_{\mathrm{AC}}^{\phi} \phi_{\mathrm{C}_{1}} /\left(\bar{V}_{\mathrm{A}}+\bar{V}_{\mathrm{C}}\right)\right]
$$

The quantities $\left(\Delta \bar{G}_{\mathrm{A}}^{\mathrm{fh}}\right)_{\mathrm{B}}^{*}$ and $\left(\Delta \bar{G}_{\mathrm{A}}^{\mathrm{fh}}\right)_{\mathrm{C}}^{*}$ are calculated from the appropriate binary reduction of eq 3 ,

$$
\left(\Delta \bar{G}_{\mathrm{A}}^{\mathrm{fh}}\right)_{\mathrm{B}}^{*}=\left(1-\phi_{\mathrm{A}}^{\mathrm{sat}}\right)^{-2} R T\left[\ln \left(\mathrm{a}_{\mathrm{A}}^{\mathrm{solid}} / \phi_{\mathrm{A}}^{\mathrm{sat}}\right)-\right.
$$

$$
\begin{gathered}
\left.\left(1-\phi_{\mathrm{A}}^{\mathrm{sat}}\right)\left(1-\frac{\bar{V}_{\mathrm{A}}}{\bar{V}_{\mathrm{B}}}\right)\right] \\
\left(\Delta \bar{G}_{\mathrm{A}}^{\mathrm{fh}}\right)_{\mathrm{C}}^{*}=\left(1-\phi_{\mathrm{A}}^{\mathrm{sat}}\right)^{-2} R T\left[\ln \left(\mathrm{a}_{\mathrm{A}}^{\mathrm{solid}} / \phi_{\mathrm{A}_{1}}^{\mathrm{sat}}\right)-\right. \\
\left.1+\bar{V}_{\mathrm{A}}\left(\frac{\phi_{\mathrm{A}_{1}}^{\mathrm{sat}}}{\bar{V}_{\mathrm{A}}}+\frac{\phi_{\mathrm{C}}}{\bar{V}_{\mathrm{C}}}\right)\right]
\end{gathered}
$$

using the molar volumes of the pure components, $\bar{V}_{i}$, and the solubilities in the pure solvents. The superscript (o) denotes that the solvent compositions are calculated as if the solute were not present.

Postulating the formation of a 1:1 anthracene:benzene complex, the authors demonstrated that eq 3 could describe the solubility of anthracene in benzene plus $n$-heptane and benzene plus isooctane mixtures to within a maximum deviation of $4 \%$ using a single value of $K_{\mathrm{AC}}^{\phi}=1.91$. More importantly, it was noted that the determination of solutesolvent equilibrium constants from solubility measurements does depend on the manner in which nonspecific interactions are incorporated into the model. In the case of anthracene solubilities, failure to include nonspecific interactions led to a calculated value of $K_{\mathrm{AC}}^{\phi}=4.07$ for the anthracene:benzene complex in solvent mixtures containing $n$-heptane.

A subsequent study by McCargar and Acree $^{2}$ compared numerical values for the carbazole-dibutyl ether association constant calculated from measured carbazole solubilities in seven binary dibutyl ether plus alkane solvent mixtures. A simple stoichiometric complexation model based entirely on specific solute-solvent interactions required two equilibrium constants to mathematically describe the experimental solubilities. Calculated equilibrium constants in cyclooctane cosolvent were significantly different from values for the isooctane cosolvent system. In comparison, eq 3 , derived from the NIBS model, described the solubility data to within an average absolute deviation of $2 \%$ using a single carbazoledibutyl ether association constant, which varied from $K_{\mathrm{AC}}^{\phi}=$ 22 for $n$-heptane to $K_{\mathrm{AC}}^{\phi}=30$ for isooctane.

Continued application of eq 3 to solubility measurements does require a prior knowledge of $\Delta \bar{G}_{\mathrm{BC}}^{\mathrm{fh}}$, which for many systems may not be easily measurable or readily available in the chemical literature. In anticipation of calculating solutedioxane association constants (e.g., carbazole-dioxane and phenol-dioxane) from solubility measurements, we decided to first measure anthracene solubilities in several binary mixtures containing $p$-dioxane in hopes of estimating $\Delta \bar{G}_{\mathrm{BC}}^{\mathrm{fh}}$ values. Solubilities are reported for anthracene in binary $p$ dioxane plus $n$-hexane, $p$-dioxane plus cyclohexane, $p$-diox- 
ane plus $n$-heptane, $p$-dioxane plus methylcyclohexane, $p$ dioxane plus $n$-octane, $p$-dioxane plus cyclooctane, and $p$ dioxane plus isooctane mixtures at $25^{\circ} \mathrm{C}$.

During the course of these studies, we explored possible correlations between the Py solvent polarity parameter and anthracene solubilities. Solvent polarity and solvatochromic parameters have been used successfully in prior solubility, chromatographic retention index, and partition coefficient correlations $^{3-7}$ for organic nonelectrolytes. The Py scale is based on the photophysical properties of pyrene in fluid solutions: ${ }^{8.9}$

$$
\begin{aligned}
\mathrm{P}+\mathrm{h} \nu_{\mathrm{o}} & \rightarrow \mathrm{P}^{*}(\text { absorption-fluorescence excitation) } \\
\mathrm{P}^{*} & \rightarrow \mathrm{P}+\mathrm{h} \nu_{1}(\text { fluorescence emission) } \\
\mathrm{P} & +\mathrm{P}^{*} \rightleftharpoons \mathrm{P}_{2}^{*}(\text { excimer formation) } \\
\mathrm{P}_{2}^{*} & \rightarrow 2 \mathrm{P}+\mathrm{h} \nu_{2}(\text { excimer emission) }
\end{aligned}
$$

The emission spectrum of the monomer consists of five major vibronic bands labeled $\mathrm{I}-\mathrm{V}$ in progressive order (i.e., the $\mathrm{O}-\mathrm{O}$ band being labeled $\mathrm{I}$, etc.). The intensities of various bands show a strong dependence on the solvent environment. A significant enhancement is observed in the $\mathrm{O}-\mathrm{O}$ vibronic band intensity in the presence of polar solvents. The ratio of emission intensities for bands III and I (Py $=$ I/III) serves as a quantitative measure of solvent polarity and structure. Structural similarity between anthracene and pyrene suggests that the Py scale might facilitate understanding of the observed maximum anthracene solubilities.

\section{Experimental Section}

Solubility Determinations-Anthracene (Aldrich; Gold Label) was used as received. Cyclohexane (Aldrich; HPLC), n-heptane (Aldrich; HPLC), $n$-hexane (Aldrich; 99\%), isooctane (Aldrich; HPLC), $n$-octane (Aldrich; Gold Label), methylcyclohexane (Aldrich; Gold Label), cyclooctane (Aldrich; Gold Label), and p-dioxane (Aldrich; HPLC) were stored over molecular sieves to remove trace water. Binary solvent mixtures were prepared by weight so that compositions could be calculated to $0.0001 \mathrm{~mol}$ fraction.

Excess solute and solvent were placed in amber glass bottles and allowed to equilibrate in a constant temperature bath at $25.0 \pm$ $0.1{ }^{\circ} \mathrm{C}$ for several days. Attainment of equilibrium was verified by repetitive measurements after several additional days and, in some instances, by approaching equilibrium from supersaturation by preequilibrating the solutions at a higher temperature. Aliquots of saturated anthracene solutions were transferred through a coarse filter into a tared volumetric flask, to determine the amount of sample, and diluted quantitatively with methanol. Concentrations were determined spectrophotometrically at $356 \mathrm{~nm}$ on a Bausch and Lomb Spectronic 2000.

Py Determinations-Pyrene (Aldrich; 99+\%) was recrystallized three times from methanol and dried at $80^{\circ} \mathrm{C}$ prior to use, and a stock solution was prepared in methanol $\left(5.7 \times 10^{-4} \mathrm{M}\right)$. Small aliquots of the stock solution were transferred into test tubes, allowed to evaporate, and subsequently diluted to $10 \mathrm{~mL}$ with the solvent of interest. The final pyrene concentration, $1 \times 10^{-6} \mathrm{M}$, was chosen to eliminate inner filtering effects. ${ }^{10}$ Cyclohexane (Aldrich; HPLC), $n$-heptane (Aldrich; HPLC), $p$-dioxane (Aldrich; HPLC), and the resulting binary solvent mixtures were optically dilute (absorbance $\mathrm{cm}{ }^{1}<0.01$ ) at all wavelengths investigated.

The fluorescence experiments were recorded on a Perkin-Elmer LS-5 spectrofluorimeter with a model 3600 data station in a $1-\mathrm{cm}^{2}$ cuvette. Excitation and emission slit widths were 10 and $3 \mathrm{~nm}$, respectively. All data were accumulated at $21^{\circ} \mathrm{C}$. Spectra obtained on the spectrofluorimeter were usually averages of five scans, which were then blank corrected. The experimental method, along with both instrumental and chemical artifacts associated with the determination of accurate Py values, is described in greater detail elsewhere. ${ }^{10}$ The excitation wavelength was $308 \mathrm{~nm}$, except for mixtures containing cyclooctane, in which case $338 \mathrm{~nm}$ was used.

\section{Results and Discussion}

The general NIBS model from which eq 3 is derived calculates the partial molar excess Gibbs free energy of the solute relative to the Flory-Huggins model of solution ideality:

$$
\begin{gathered}
R T\left[\ln \left(\mathrm{a}_{\mathrm{A}}^{\text {solid }} / \phi_{\mathrm{A}}^{\mathrm{sat}}\right)-\left(1-\phi_{\mathrm{A}}^{\mathrm{sat}}\right)\left(1-\frac{\bar{V}_{\mathrm{A}}}{X_{\mathrm{B}}^{\mathrm{o}} \bar{V}_{\mathrm{B}}+X_{\mathrm{C}}^{\mathrm{o}} \bar{V}_{\mathrm{C}}}\right]\right. \\
=\left(1-\phi_{\mathrm{A}}^{\mathrm{sat}}\right)^{2}\left[\phi_{\mathrm{B}}^{\mathrm{o}}\left(\Delta \bar{G}_{\mathrm{A}}^{\mathrm{fh}}\right)_{\mathrm{B}}^{*}+\phi_{\mathrm{C}}^{\mathrm{o}}\left(\Delta \bar{G}_{\mathrm{A}}^{\mathrm{fh}}\right)_{\mathrm{C}}^{*}-\right. \\
\left.\bar{V}_{\mathrm{A}}\left(X_{\mathrm{B}}^{\mathrm{o}} \bar{V}_{\mathrm{B}}+X_{\mathrm{C}}^{\mathrm{o}} \bar{V}_{\mathrm{C}}\right)^{-1} \Delta \bar{G}_{\mathrm{BC}}^{\mathrm{fh}}\right]
\end{gathered}
$$

To date, the basic NIBS model has been shown to provide very reasonable predictions of iodine, naphthalene, benzil, $p$ benzoquinone, biphenyl, anthracene, stannic iodide, and pyrene solubilities in binary solvent mixtures containing only nonspecific interactions. ${ }^{11}$ Predictive application of eq 4 requires a prior knowledge of solute solubility in each pure solvent, the excess Gibbs free energy of the binary solvent mixture, and the numerical value of $\mathrm{a}_{\mathrm{A}}^{\text {solid }}$ which is calculated from

$$
\ln \mathrm{a}_{\mathrm{A}}^{\text {solid }}=\frac{-\Delta H_{\mathrm{A}}^{\text {fus }}\left(T_{\mathrm{mp}}-T\right)}{R T T_{\mathrm{mp}}}
$$

the enthalpy of fusion, $\Delta \bar{H}_{\mathrm{A}}^{\text {fus }}$, of the solute at its normal melting point temperature $T_{\mathrm{mp}}$.

Lack of experimental $\Delta \bar{G}_{\mathrm{BC}}^{\mathrm{fh}}$ values for all but three of the binary $p$-dioxane plus alkane systems studied does limit, to a large extent, the predictive application of eq 5 . These $\Delta \bar{G}_{\mathrm{BC}}^{\mathrm{fh}}$ values can be estimated from the measured anthracene solubilities listed in Table I. Table II compares estimated $\Delta \bar{G}_{\mathrm{BC}}^{\mathrm{fh}}$ values with experimental values ${ }^{12,13}$ for $p$-dioxane plus $n$-heptane, $p$-dioxane plus cyclohexane, and $p$-dioxane plus methylcyclohexane mixtures. Properties used in these calculations are listed in Table III. Excess Gibbs free energies, calculated from experimental anthracene solubilities using the basic NIBS model (eq 3 with $K_{\mathrm{AC}}^{\phi}=0$ ), are large positive values, thus suggesting that binary $p$-dioxane plus alkane mixtures are quite nonideal. Large positive deviations from ideality mathematically account for pronounced maximum mole fraction solubilities of anthracene observed in the three binary $p$-dioxane plus cycloalkane systems studied.

Inspection of the last two columns of Table II reveals that reasonable excess Gibbs free energies can be obtained from the NIBS model. Estimated values are by no means perfect, but are of sufficient accuracy for use in subsequent solubility studies involving solute-dioxane association. Unlike other methods ${ }^{14-19}$ for determining solute-solvent association constants from solubility measurements, the extended NIBS approach does incorporate the nonideality of the binary solvent mixture into the calculations. For the three $p$-dioxane systems compared, estimated $\Delta \bar{G}_{\mathrm{BC}}^{\mathrm{fh}}$ values are consistently $20-60 \mathrm{cal} / \mathrm{mol}$ larger than experimental values which are believed to be accurate to about $\pm 20 \mathrm{cal} / \mathrm{mol}$. Mathematically, an overestimate of $\Delta \bar{G}_{\mathrm{BC}}^{\mathrm{fh}}$ requires that anthracene must be more soluble in binary solvent mixtures than would be expected based on eq 5 for nonspecific interactions. This enhanced solubility can be explained by assuming that a small specific dipole-induced dipole interaction occurs between the oxygen lone electron pairs on $p$-dioxane and the anthracene polarizable $\pi$-electron cloud. Specific interaction 
Table 1-Solubility of Anthracene in Several Binary Solvent Systems

\begin{tabular}{|c|c|c|}
\hline Solvent (C) + Solvent (B) & $X_{\mathrm{C}}^{\circ}$ & $X_{A}^{\text {sat a }}$ \\
\hline$p$-Dioxane $+n$-Hexane & $\begin{array}{l}0.0000 \\
0.1503 \\
0.2837 \\
0.5034 \\
0.5089 \\
0.6036 \\
0.6044 \\
0.6953 \\
0.6988 \\
0.8581 \\
0.8615 \\
1.0000\end{array}$ & $\begin{array}{l}0.001273 \\
0.002216 \\
0.003292 \\
0.005325 \\
0.005381 \\
0.006383 \\
0.006438 \\
0.007337 \\
0.007371 \\
0.008562 \\
0.008563 \\
0.008381\end{array}$ \\
\hline 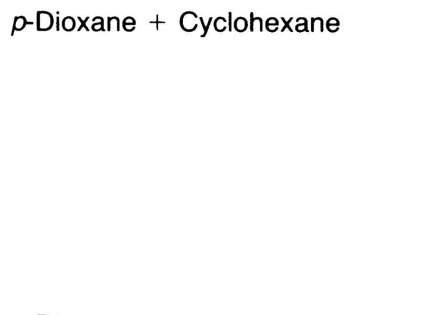 & $\begin{array}{l}0.0000 \\
0.1338 \\
0.2471 \\
0.4557 \\
0.5574 \\
0.6580 \\
0.7381 \\
0.8399 \\
0.9087 \\
1.0000\end{array}$ & $\begin{array}{ll}0.001 & 551 \\
0.002 & 676 \\
0.003 & 883 \\
0.006 & 194 \\
0.007 & 125 \\
0.008 & 052 \\
0.008 & 408 \\
0.009 & 073 \\
0.008 & 688 \\
0.008 & 381\end{array}$ \\
\hline$p$-Dioxane $+n$-Heptane & $\begin{array}{l}0.0000 \\
0.1573 \\
0.3048 \\
0.5286 \\
0.6381 \\
0.7181 \\
0.8733 \\
1.0000\end{array}$ & $\begin{array}{l}0.001568 \\
0.002482 \\
0.003610 \\
0.005723 \\
0.006797 \\
0.007586 \\
0.008482 \\
0.008381\end{array}$ \\
\hline p-Dioxane + Methylcyclohexane & $\begin{array}{l}0.0000 \\
0.1425 \\
0.2660 \\
0.5008 \\
0.5999 \\
0.6912 \\
0.7721 \\
0.8529 \\
0.9205 \\
1.0000\end{array}$ & $\begin{array}{l}0.001652 \\
0.002799 \\
0.003913 \\
0.006250 \\
0.007165 \\
0.007937 \\
0.008466 \\
0.008813 \\
0.008640 \\
0.008381\end{array}$ \\
\hline$p$-Dioxane $+n$-Octane & $\begin{array}{l}0.0000 \\
0.1841 \\
0.3295 \\
0.5568 \\
0.6555 \\
0.7432 \\
0.8813 \\
0.9406 \\
1.0000\end{array}$ & $\begin{array}{l}0.001836 \\
0.002903 \\
0.004040 \\
0.006131 \\
0.007042 \\
0.007808 \\
0.008815 \\
0.008519 \\
0.008381\end{array}$ \\
\hline p-Dioxane + Cyclooctane & $\begin{array}{l}0.0000 \\
0.1497 \\
0.2855 \\
0.5078 \\
0.6128 \\
0.7008 \\
0.7842 \\
0.8580 \\
0.9329 \\
1.0000\end{array}$ & $\begin{array}{l}0.002251 \\
0.003654 \\
0.005122 \\
0.007462 \\
0.008338 \\
0.008896 \\
0.009281 \\
0.009339 \\
0.008893 \\
0.008381\end{array}$ \\
\hline$p$-Dioxane + Isooctane & $\begin{array}{l}0.0000 \\
0.1886 \\
0.3320 \\
0.5566 \\
0.6594 \\
0.7491 \\
0.8850 \\
1.0000\end{array}$ & $\begin{array}{l}0.001067 \\
0.001927 \\
0.002891 \\
0.004903 \\
0.005988 \\
0.006942 \\
0.008121 \\
0.008381\end{array}$ \\
\hline
\end{tabular}

${ }^{a}$ Numerical values represent the average of 4-8 independent determinations, with the measurements being reproducible to within $\pm 1 \%$; solubilities in the pure alkane solvents are in excellent agreement with values reported in ref 23 ; determined at $25^{\circ} \mathrm{C}$.
Table II-Excess Gibbs Free Energy of Binary p-Dioxane Plus Alkane Systems Estimated from Anthracene Solubilities

\begin{tabular}{|c|c|c|c|}
\hline Component $(\mathrm{C})+$ Component $(\mathrm{B})$ & $X_{\mathrm{C}}^{\circ}$ & $\Delta \bar{G}_{\mathrm{BC}}^{\mathrm{fh}}{ }^{a}$ & $\Delta \bar{G}_{B C}^{\text {fh,exp }}$ \\
\hline$p$-Dioxane $+n$-Hexane & $\begin{array}{l}0.1503 \\
0.2837 \\
0.5034 \\
0.5089 \\
0.6036 \\
0.6044 \\
0.6953 \\
0.6988 \\
0.8581 \\
0.861\end{array}$ & $\begin{array}{l}181 \\
270 \\
300 \\
300 \\
285 \\
287 \\
254 \\
252 \\
152 \\
149\end{array}$ & $\begin{array}{l}- \\
- \\
- \\
- \\
- \\
-\end{array}$ \\
\hline$p$-Dioxane + Cyclohexane & $\begin{array}{l}0.1338 \\
0.247 \\
0.4557 \\
0.5574 \\
0.6580 \\
0.7381 \\
0.8399 \\
0.9087\end{array}$ & $\begin{array}{r}151 \\
233 \\
279 \\
261 \\
236 \\
193 \\
146 \\
80\end{array}$ & $\begin{array}{r}120 \\
187 \\
239 \\
236 \\
214 \\
183 \\
127 \\
78\end{array}$ \\
\hline$p$-Dioxane $+n$-Heptane & $\begin{array}{l}0.1573 \\
0.3048 \\
0.5286 \\
0.6381 \\
0.7181 \\
0.8733\end{array}$ & $\begin{array}{l}168 \\
263 \\
302 \\
279 \\
248 \\
136\end{array}$ & $\begin{array}{l}134 \\
210 \\
239 \\
218 \\
189 \\
101\end{array}$ \\
\hline$p$-Dioxane + Methylcyclohexane & $\begin{array}{l}0.1425 \\
0.2660 \\
0.5008 \\
0.5999 \\
0.6912 \\
0.7721 \\
0.8529 \\
0.9205\end{array}$ & $\begin{array}{r}179 \\
257 \\
294 \\
274 \\
240 \\
198 \\
144 \\
79\end{array}$ & $\begin{array}{r}113 \\
178 \\
225 \\
216 \\
194 \\
162 \\
117 \\
69\end{array}$ \\
\hline$p$-Dioxane $+n$-Octane & $\begin{array}{l}0.1841 \\
0.3295 \\
0.5568 \\
0.6555 \\
0.7432 \\
0.8813 \\
0.9406\end{array}$ & $\begin{array}{r}188 \\
279 \\
310 \\
282 \\
241 \\
147 \\
70\end{array}$ & $\begin{array}{l}- \\
- \\
- \\
- \\
-\end{array}$ \\
\hline$p$-Dioxane + Isooctane & $\begin{array}{l}0.1886 \\
0.3320 \\
0.556 \\
0.659 \\
0.749 \\
0.885\end{array}$ & $\begin{array}{l}235 \\
338 \\
367 \\
333 \\
280 \\
155\end{array}$ & $\begin{array}{l}- \\
- \\
- \\
-\end{array}$ \\
\hline$p$-Dioxane + Cyclooctane & $\begin{array}{l}0.1497 \\
0.2855 \\
0.5078 \\
0.6128 \\
0.7008 \\
0.7842 \\
0.8580 \\
0.9329\end{array}$ & $\begin{array}{r}181 \\
273 \\
305 \\
280 \\
244 \\
199 \\
146 \\
71\end{array}$ & $\begin{array}{l}- \\
- \\
- \\
- \\
-\end{array}$ \\
\hline
\end{tabular}

${ }^{a}$ Units of $\Delta \bar{G}_{\mathrm{BC}}^{\text {th }}$ values are $\mathrm{cal} / \mathrm{mol}$.

Table III-Properties Used in $\Delta \bar{G}_{B C}^{\text {th }}$ Calculations

\begin{tabular}{lcl}
\hline \multicolumn{1}{c}{ Component $(I)$} & $\bar{V}_{i}, \mathrm{~cm}^{3} / \mathrm{mol}$ \\
\hline$p$-Dioxane & 85.72 & \\
$n$-Hexane & 131.51 & \\
Cyclohexane & 108.76 & \\
$n$-Heptane & 147.48 & \\
Methylcyclohexane & 128.32 & \\
$n$-Octane & 163.46 & $\mathrm{a}_{A}^{\text {solid }}=0.01049^{a}$ \\
Isooctane & 166.09 & 134.88 \\
Cyclooctane & $150.00^{a}$ & \\
Anthracene &
\end{tabular}

${ }^{a}$ Values taken from ref 23 
seems possible from steric considerations as $p$-dioxane favors a chair conformation ${ }^{20}$ where the electron pairs would be readily accessible to surrounding solute molecules.

The Py scale measures effects that solvent polarity has on the fluorescence properties of an aromatic pyrene molecule. Structural similarities between anthracene and pyrene suggest that if the presumed specific anthracene-dioxane interaction is large, there might be a correlation between measured solubilities and the Py scale. Numerical Py values are calculated as the ratio of emission intensities for bands III and $\mathrm{I}(\mathrm{Py}=\mathrm{I} / \mathrm{III})$ of the monomer spectrum. Figure 1 is a three-dimensional stack (all spectra normalized to band III) showing emission intensity variation as a function of both wavelength and composition for the $p$-dioxane and cyclohexane system. Significant enhancement is observed in the first peak with increasing $p$-dioxane concentration. Values for the pure solvents cyclohexane, isooctane, and $p$-dioxane (reproducibility to within \pm 0.02 ) are slightly less than the values of $0.58,0.59$, and 1.50 reported by Dong and Winnik ${ }^{9}$ for a $1-\mathrm{nm}$ emission slit width. The slit width does affect the calculated value of Py. An earlier study ${ }^{21}$ of binary tetrahydrofuran plus methanol and dimethylformamide plus water mixtures suggested that the general shape of the Py versus solvent composition curve is not significantly affected by slit width.

As summarized in Figure 2, Py values for the four binary $p$-dioxane plus alkane systems vary smoothly with volume fraction composition and are nearly superimposible within

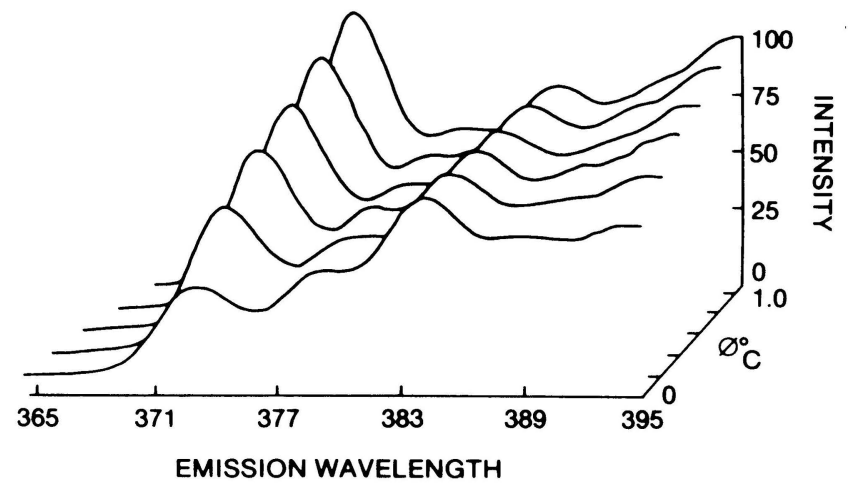

Figure 1-Three-dimensional stack of emission intensities versus wavelength and volume fraction of p-dioxane for binary mixtures containing cyclohexane. Spectra have been scaled to equivalent emission intensities for peak III.

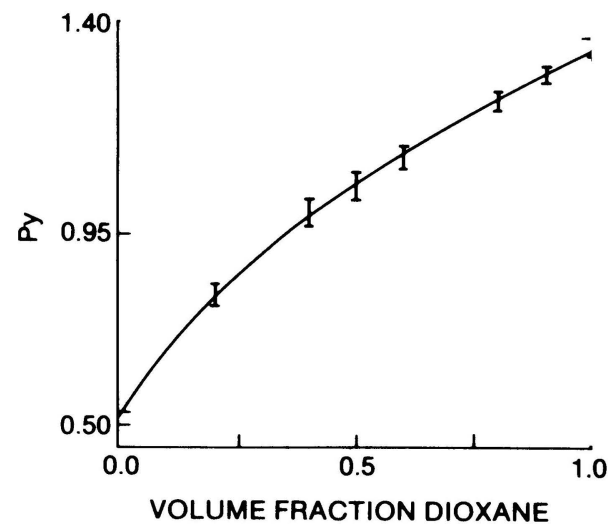

Figure 2-Py versus volume fraction of p-dioxane for binary solvent mixtures containing cosolvents $n$-heptane, cyclohexane, cyclooctane, and isooctane. Curves for the four binary systems are nearly superimposible within experimental reproducibility. experimental reproducibility. In comparison, anthracene solubilities in the three binary cycloalkane systems show a pronounced maxima around $X_{\text {dioxane }}^{\mathrm{o}}=0.85$. Apparent lack of correlation between anthracene solubilities and the Py solvent polarity scale suggests that specific anthracene-dioxane interactions are indeed weak or nonexistent. Furthermore, the basic NIBS model (with $K_{\mathrm{AC}}^{\phi}=0$ ) does predict anthracene solubilities to within $+15 \%$ in the three binary $p$-dioxane plus alkane solvent systems for which experimental $\Delta \bar{G}_{\mathrm{BC}}^{\mathrm{fh}}$ values are available. The basic NIBS model does underpredict the experimental solubility, and better predictions can be obtained by introducing a very small equilibrium constant, $K_{\mathrm{AC}}^{\phi}$ of $4-7\left(K_{\mathrm{AC}}^{\mathrm{c}} \approx 0.4\right)$. Readers are reminded that the calculation of such a small anthracene-dioxane equilibrium constant does not prove that such complexes are actually present in solution, as Higuchi and Connors ${ }^{22}$ have stated that molar equilibrium constants, $K_{\mathrm{AC}}^{\mathrm{c}}$, of less than unity are inconclusive. The existence of molecular complexes in solution should be supported by independent and more definitive spectroscopic, calorimetric, et cetera, measurements.

\section{Glossary}

$\mathrm{a}_{\mathrm{A}}^{\text {solid }}$ Activity of the solid solute, defined as the ratio of the fugacity of the solid to the fugacity of the pure subcooled liquid.

$\left(\Delta G_{\mathrm{A}}^{\mathrm{fh}}\right) * \quad$ Partial molar Gibbs free energy of the solute based on the Flory-Huggins model, extrapolated back to infinite dilution.

$\Delta \bar{G}_{\mathrm{BC}}^{\mathrm{fh}} \quad$ Excess Gibbs free energy of the binary solvent mixture $\bar{V} \quad$ based on the Flory-Huggins model of solution ideality.

$\bar{V}_{i} \quad$ Molar volume of component $i$.

$X_{\mathrm{B}}^{\mathrm{o}}, X_{\mathrm{C}}^{\mathrm{o}} \quad$ Mole fraction compositions of the solvent mixture, calculated as if the solute were not present.

$X_{\mathrm{A}}^{\mathrm{sat}} \quad$ Mole fraction solubility of solute.

$\phi_{\mathrm{B}}^{\mathrm{o}}, \phi_{\mathrm{C}}^{\mathrm{o}} \quad$ Ideal volume fraction composition of the solvent mixture, calculated as if the solute were not present.

$\phi_{\mathrm{A}}^{\text {sat }} \quad$ Ideal volume fraction solubility of solute.

\section{References and Notes}

1. Acree, W. E., Jr.; McHan, D. R.; Rytting, J. H. J. Pharm. Sci. 1983, 72, 929-934.

2. McCargar, J. W.; Acree, W. E., Jr., submitted for publication in Phys. Chem. Liq.

3. Kamlet, M. J.; Abraham, M. H.; Doherty, R. M.; Taft, R. W. J. Am. Chem. Soc. 1984, 106, 464-466.

4. Taft, R. W.; Abraham, M. H.; Famini, G. R.; Doherty, R. M.; Abboud, J.-L. M.; Kamlet, M. J. J. Pharm. Sci. 1985, 74, 807814.

5. Taft, R. W.; Abraham, M. H.; Doherty, R. M.; Kamlet, M. J. Nature 1985, 313, 384-386.

6. Kamlet, M. J.; Doherty, R. M.; Abboud, J.-L. M.; Abraham, M. H.; Taft, R. W. J. Pharm. Sci. 1986, 75, 338-349.

7. Johnson, B. P.; Khaledi, M. G.; Dorsey, J. G. Anal. Chem. 1986 $58,2354-2365$.

8. Dong, D. C.; Winnik, M. A. Photochem. Photobiol. 1982, 35, 1721.

9. Dong, D. C.; Winnik, M. A. Can. J. Chem. 1984, 62, 2560-2565.

10. Street, K. W., Jr.; Acree, W. E., Jr. Analyst 1986, 111, 11971201. 
11. Acree, W. E., Jr. Thermodynamic Properties of Nonelectrolyte Solutions; Academic: Orlando, FL, 1984.

12. Deshpande, D. D.; Oswal, S. L. J. Chem. Thermodyn. 1975, 7, $155-159$.

13. Jain, D. V. S.; Sidhu, R. S. J. Chem. Thermodyn. 1984, 16, 111114.

14. Pipkin, J. D.; Stella, V. J. Int. J. Pharm. 1983, 14, 263-277.

15. Mehdizadeh, M.; Grant, D. J. W. J. Pharm. Sci. 1984, 73, 11951202.

16. Iga, K.; Hussain, A.; Kashihara, T. J. Pharm. Sci. 1981, 70, 108109 .

17. James, K. C.; Mehdizadeh, M. J. Pharm. Pharmacol. 1981, 33, $9-13$.

18. Fung, H.-L.; Higuchi, T. J. Pharm. Sci. 1971, 60, 1782-1788.

19. Anderson, B. D.; Rytting, J. H.; Higuchi, T. J. Pharm. Sci. 1980, $69,676-680$
20. Gould, E. S. Mechanism and Structure in Organic Chemistry; Holt, Rinehart and Winston: New York, NY, 1959

21. Street, K. W., Jr.; Acree, W. E., Jr. J. Liq. Chromatogr. 1986, 9 , $2799-2808$.

22. Higuchi, T.; Connors, K. A. Adv. Anal. Chem. Instr. 1965, 4 , $117-212$.

23. Acree, W. E., Jr.; Rytting, J. H. J. Pharm. Sci. 1983, 72, 292 296.

\section{Acknowledgments}

Acknowledgment is made to the Donors of the Petroleum Research Fund, administered by the American Chemical Society, for partial support of this research. 